\title{
Differential Distribution of Functional Receptors for Neuromodulators Evoking Short-Term Heterosynaptic Plasticity in Aplysia Sensory Neurons
}

\author{
Zhong-Yi Sun, Beth Kauderer, and Samuel Schacher \\ Center for Neurobiology and Behavior, Columbia University College of Physicians and Surgeons, and New York State \\ Psychiatric Institute, New York, New York 10032
}

\begin{abstract}
Synaptic transmission and excitability in Aplysia sensory neurons (SNs) are bidirectionally modulated by $5-\mathrm{HT}$ and FMRFamide. To explore the regional distribution of different functional receptors that modulate $\mathrm{SN}$ properties, we examined changes in synaptic efficacy and excitability with brief focal applications of the neuromodulators to different regions of SNs that have established connections with motor cell L7 in culture. Short-term changes in synaptic efficacy were evoked only when $5-\mathrm{HT}$ or FMRFamide was applied to regions with $\mathrm{SN}$ varicosities along the surface of $\mathrm{L} 7$ axons. Applications to adjacent $\mathrm{SN}$ neurites with few varicosities in contact with $\mathrm{L} 7$ axons failed to evoke a significant change in synaptic efficacy. The distribution of functional receptors mediating changes in excitability differed for 5-HT and FMRFamide. Whereas excitability increases
\end{abstract}

were evoked only when 5-HT was applied to $\mathrm{SN}$ cell bodies, excitability decreases in SNs were evoked only when FMRFamide was applied to regions along the $\mathrm{L} 7$ axon with $\mathrm{SN}$ varicosities. Without the target cell, cell bodies of SNs expressed both $5-\mathrm{HT}$ and FMRFamide receptors that modulate excitability. These results indicate that functional G-proteincoupled receptors for two neuromodulators are distributed differentially along the surface of a presynaptic neuron that forms chemical connections in vitro. This differential distribution of receptors on the presynaptic neuron is regulated by a target and does not require the physical presence of neurons that release the neuromodulators.

key words: serotonin receptors; FMRFamide receptors; synaptic plasticity; excitability; short-term; Aplysia; sensory neuron
The expression and distribution of neurotransmitter receptors are critical for information transfer between neuron and target. Synapse formation is accompanied by the correct apposition of presynaptic transmitter release sites and postsynaptic membrane with a high density of ionotropic receptors. This process appears to be mediated by a complex set of reciprocal interactions via diffusible or contact-mediated signals between presynaptic neuron and postsynaptic target (Anderson and Cohen, 1977; Frank and Fischbach, 1979; McMahan and Wallace, 1989; Falls et al., 1990; Zoran et al., 1990; Hall and Sanes, 1993; Dan and Poo; 1994; Drapeau et al., 1995). Neurons also contain other types of neurotransmitter receptors, such as those coupled via G-proteins to second-messenger cascades, that can modulate synaptic transmission and/or membrane excitability. How is the distribution of these receptors regulated? Are different receptors on a given neuron distributed in similar ways? Is the appropriate distribution of G-protein-coupled receptors regulated by interactions with neurons that synthesize and release the neuromodulator?

Many sensory neurons (SNs) of Aplysia appear to utilize amino acids to evoke fast excitatory responses in follower cells (Dale and Kandel, 1993; Trudeau and Castellucci, 1993; Gapon and Kupfermann, 1996). Synaptic transmission from SN terminals can undergo short-term bidirectional changes via the release from

\footnotetext{
Received Aug. 30, 1996; revised Sept. 17, 1996; accepted Sept. 18, 1996.

This research was supported by National Institutes of Health Grants GM 32099 and NS 27541. We thank Robert Woolley for assistance in preparing these figures, and Drs. J. Koester and I. Kupfermann for helpful comments on earlier drafts of this manuscript.

Correspondence should be addressed to Samuel Schacher, Center for Neurobiology and Behavior, Columbia University College of Physicians and Surgeons, New York State Psychiatric Institute, 722 West 168th Street, New York, NY 10032.

Copyright (C) 1996 Society for Neuroscience $0270-6474 / 96 / 167540-10 \$ 05.00 / 0$
}

interneurons of transmitters such as 5-HT (facilitation) and FMRFamide (depression) that act as neuromodulators of SN properties (Brunelli et al., 1976; Belardetti et al., 1987; Glanzman et al., 1989b; Mackey et al., 1989; Rosen et al., 1989; Small et al., 1992; Xu et al., 1994). Both 5-HT and FMRFamide also evoke changes in SN excitability (Klein et al., 1986; Critz et al., 1991). Short-term changes in synaptic efficacy require the presence of 5-HT and FMRFamide in the general region of SN terminals, whereas short-term excitability increases require the actions of 5 -HT in the general region of the SN cell body (Clark and Kandel, 1984; Hammer et al., 1989; Clark and Cooper, 1993; Emptage and Carew, 1993). These neuromodulators activate second-messenger cascades in SNs that affect both ion channel conductances and transmitter release processes (Castellucci et al., 1980; Klein et al., 1980; Bernier et al., 1982; Siegelbaum et al., 1982; Occor and Byrne, 1985; Hochner et al., 1986; Belardetti et al., 1987; Piomelli et al., 1987; Baxter and Byrne, 1989; Buttner et al., 1989; Braha et al., 1990; Saktor and Schwartz, 1990; Pieroni and Byrne, 1992; Sossin and Schwartz, 1992; Sugita et al., 1992; Byrne and Kandel, 1996). Because the terminals and cell body are distant from each other, second-messenger-mediated changes affecting synaptic transmission at SN terminals and excitability changes at the cell body may require the local actions of the modulatory neurotransmitters. In addition, recent in vivo and in vitro studies indicate that at least two types of 5-HT receptors are expressed by SNs and that they contribute differentially to plasticity of SN properties (Mercer et al., 1991; Emptage and Carew, 1993; Li et al., 1995; Sun and Schacher, 1996). These studies, however, did not examine the relative distribution of the 5-HT receptor subtypes or FMRFamide receptors along the surface of the SN cell body, axon, neurites, and terminals or how the distributions are regulated. 
To explore the distribution of G-protein-coupled receptors on the surface of SNs, we examined short-term changes in synaptic efficacy and excitability evoked by brief focal applications of 5-HT and FMRFamide on different regions of the SNs (cell body, axon, regenerated neurites, and terminal varicosities) that have established synaptic contacts along the axons of motor cell L7 in cell culture. Short-term changes in synaptic efficacy were evoked only when the neuromodulators were applied to regions with SN varicosities. Excitability was increased only when 5-HT was applied to the SN cell body. By contrast, excitability was decreased only when FMRFamide was applied to regions with SN varicosities. The distribution of functional FMRFamide and 5-HT receptors on $\mathrm{SN}$ cell bodies was regulated by the target motor cell. These results, and those recently reported on the time-dependent expression of functional 5-HT receptors in culture (Sun and Schacher, 1996), indicate that functional G-protein-coupled receptors mediating plasticity are enriched at specific locations along the regenerated neurites and varicosities of SNs. The distribution of functional receptors on $\mathrm{SNs}$ is neuromodulatorspecific and is regulated by interaction with a target neuron, but it does not require direct interaction with interneurons that release the neuromodulators.

\section{MATERIALS AND METHODS}

Cell culture. Mechanosensory neurons (SNs) of Aplysia were isolated from the pleural ganglion dissected from adult animals $(70-100 \mathrm{gm})$ and cocultured with identified motor cell L7 isolated from the abdominal ganglion of juvenile animals (1-3 gm; University of Miami Aplysia Mariculture Facility) and maintained for $4 \mathrm{~d}$ as described previously (Schacher, 1985; Rayport and Schacher, 1986; Glanzman et al., 1989a; Goldberg and Schacher, 1996). Individual cells were isolated with an intact segment $(100-800 \mu \mathrm{m})$ of their original axons (Schacher and Proshansky, 1983). Each culture contained a single SN with an L7. Individual SNs were plated in some of the same dishes as the cocultures but in a location distant from the interacting cells. These SNs were used to measure changes in excitability in the absence of a target. Cells were allowed to grow processes for $4 \mathrm{~d}$ to permit the establishment of stable synaptic contacts and neuritic arbors (Montarolo et al., 1986; Glanzman et al., 1990).

Electrophysiology. The stimulation and recording techniques for measuring neuromodulator-induced changes in the amplitude of the EPSP evoked in L7 (synaptic efficacy) for both nondepressed and depressed SN-L7 connections and for monitoring changes in electrical excitability of SNs in culture have been described previously (Montarolo et al., 1986, 1988; Dale et al., 1987, 1988; Sun and Schacher, 1996). To monitor changes in EPSP amplitude, the motor cell was impaled with a microelectrode (15-20 M $\Omega$ ) containing $2.0 \mathrm{M} \mathrm{K}$-acetate, $0.5 \mathrm{M} \mathrm{KCl}$, and $10 \mathrm{~mm}$ K-HEPES, $\mathrm{pH} 7.4$, and was held at a potential of $-85 \mathrm{mV}$ to permit accurate measurement of the amplitude of the EPSP. Synaptic potentials were evoked in $\mathrm{L} 7$ by stimulating each SN with a brief $(0.4-0.6 \mathrm{msec})$ depolarizing pulse using an extracellular electrode placed near the cell body of the SN. For measuring changes in efficacy at nondepressed synapses, EPSP amplitudes were measured both $10 \mathrm{~min}$ before and $15 \mathrm{sec}$ after brief focal applications of neuromodulator (see below). The effects of focal applications of neuromodulators on depressed synapses were measured $10 \mathrm{sec}$ after a $20 \mathrm{sec}$ application of neuromodulator after first producing homosynaptic depression of the connection with 10-12 stimuli to the SN at $30 \mathrm{sec}$ intervals (Sun and Schacher, 1996). These stimuli depress the EPSPs to $\sim 30 \%$ of their initial value. We also measured neuromodulator-induced changes in postsynaptic conductance at two holding potentials $(-60$ and $-80 \mathrm{mV})$. Constant-current pulses $( \pm 0.2$ $\mathrm{nA}, 2 \mathrm{sec}$ duration) at $5 \mathrm{sec}$ intervals were given to L7 in SN-L7 cultures before, during, and after a $25 \mathrm{sec}$ application of neuromodulator to a region along the $\mathrm{L} 7$ axon with a high density of $\mathrm{SN}$ varicosities. Changes in SN excitability were determined by monitoring the number of action potentials evoked in SNs held at the resting potential $(-40$ to $-48 \mathrm{mV})$ by a $500 \mathrm{msec}$ depolarizing current pulse via intracellular electrodes (see above) before and $10 \mathrm{sec}$ after focal application of neuromodulator. Successive current pulses were given at 1 min intervals. To measure increases in excitability with 5-HT, the initial current level was adjusted before treatment to the threshold for evoking a single action potential. To measure the decrease in excitability with FMRFamide, the initial current level was adjusted for each SN to $50 \%$ above the threshold level for evoking a single action potential. Changes in excitability reversed within $1 \mathrm{~min}$ of neuromodulator application.

Dye injection and imaging $S N$ neurites and varicosities. One hour before recording the initial amplitude of the EPSP, fluorescent dye 5(6)carboxyfluorescein (Molecular Probes; $6 \%$ in $0.44 \mathrm{M} \mathrm{KOH,} \mathrm{pH}=7.0$ ) was injected into the $\mathrm{SN}$ with $0.4-0.6 \mathrm{nA}$ hyperpolarizing current pulses (500 msec at $1 \mathrm{~Hz}$ ) for 5-6 min (Glanzman et al., 1989a). Phase-contrast and fluorescent images of the same view areas along the major axon of the motor cell were taken to map out the location of SN varicosities and neurites to identify appropriate zones for focal applications of the neuromodulators. A Nikon Diaphot microscope with an SIT (Dage) video camera linked to a Dell 310 computer with a PC Vision Plus frame grabber was used to process and store the images for subsequent electrophysiological examination. Images were subsequently stored on a Storage Dimension or Panasonic optical disk drive. Illumination used for obtaining fluorescent images was kept as low as possible to prevent photodamage. Micrographs of the images were made with a Panasonic or Sony video printer.

Transmitter applications. Transmitters were applied focally by pressure ejection via micropipette containing solutions of the neuromodulators in perfusion medium [1:1 by volume of L-15 medium (Sigma, St. Louis, MO) with appropriate salts added to reflect marine environment of Aplysia and seawater (Instant Ocean) (Montarolo et al., 1988)] with $0.02 \%$ Fast Green to visualize the location of the stream (Stoop and Poo, 1995) (see Fig. 1). A second micropipette attached to a vacuum was positioned near the ejection pipette for rapid removal of neuromodulator. The width of the stream across the selected region of interest was controlled by the pressure used to eject solutions, the placement of the pipettes containing the neuromodulator and the one attached to the vacuum used to remove the neuromodulator (see Fig. 1) (Stoop and Poo, 1995). The widths of the streams used in this study were $40-60 \mu \mathrm{m}$. This method could be used to generate streams as small as $5 \mu \mathrm{m}$. The neuromodulators were applied while L7 was maintained at the resting potential (range -55 to $-62 \mathrm{mV}$ ) to one of four areas: regions containing SN varicosities or SN neurites (e.g., Fig. $1 A, B$ ) as determined by the epifluorescent and phase-contrast images; the SN cell body (Fig. 1C); and initial axon segment of the SN (Fig. 1D). Applications of the neuromodulators to regions with $\mathrm{SN}$ varicosities or adjacent neurites in contact with the axon of L7 occasionally ( $\sim 20 \%$ of cultures) evoked small $( \pm 1-2 \mathrm{mV})$ transient changes in L7 membrane potential. In addition, little or no detectable changes in L7 membrane conductance $(0$ to $\pm 10 \%)$ were evoked by 5 -HT ( $n=4$ cocultures) or FMRFamide ( $n=4$ cocultures) applied to the motor axon that contained $\mathrm{SN}$ varicosities at the different holding potentials. The micropipettes for ejecting neuromodulators contained either $50 \mu \mathrm{M}$ 5-HT (Sigma) or $10 \mu \mathrm{M}$ FMRFamide (Peninsula). Ejections lasting $20-25 \mathrm{sec}$ were used to generate changes in synaptic efficacy and excitability. In some cultures, we applied neuromodulator to some regions for up to $60 \mathrm{sec}$ (see Results). Results obtained with the long applications were pooled with results of the short applications. Changes in efficacy of nondepressed synapses or in excitability were measured 10-15 sec after application, whereas changes in efficacy of depressed synapses were tested with two stimuli at the designated $30 \mathrm{sec}$ intervals (the first stimulus was $\sim 10 \mathrm{sec}$ after application of neuromodulator).

Analysis of data. All data are represented as mean \pm SEM. ANOVAs (one- or two-factor) followed by corrected multicomparison tests (Dunnett's or Scheffe's $F$ test) were used to measure significance of differences between control and experimental groups or between specific experimental groups.

\section{RESULTS}

\section{Neuromodulators evoke changes in synapse efficacy only when applied at or near $\mathrm{SN}$ varicosities}

Synapses between SN and motor cell L7 form rapidly in cell culture and are stable by day 4 in culture (Glanzman et al., 1990; Bank and Schacher, 1992; Zhu et al., 1994). Evidence indicates that $\mathrm{SN}$ varicosities in contact with the main motor axon are the primary sites of synaptic interaction. The number of SN varicosities in contact with the motor cell axon correlates with the efficacy of the synapse as the connections between the cells are established 

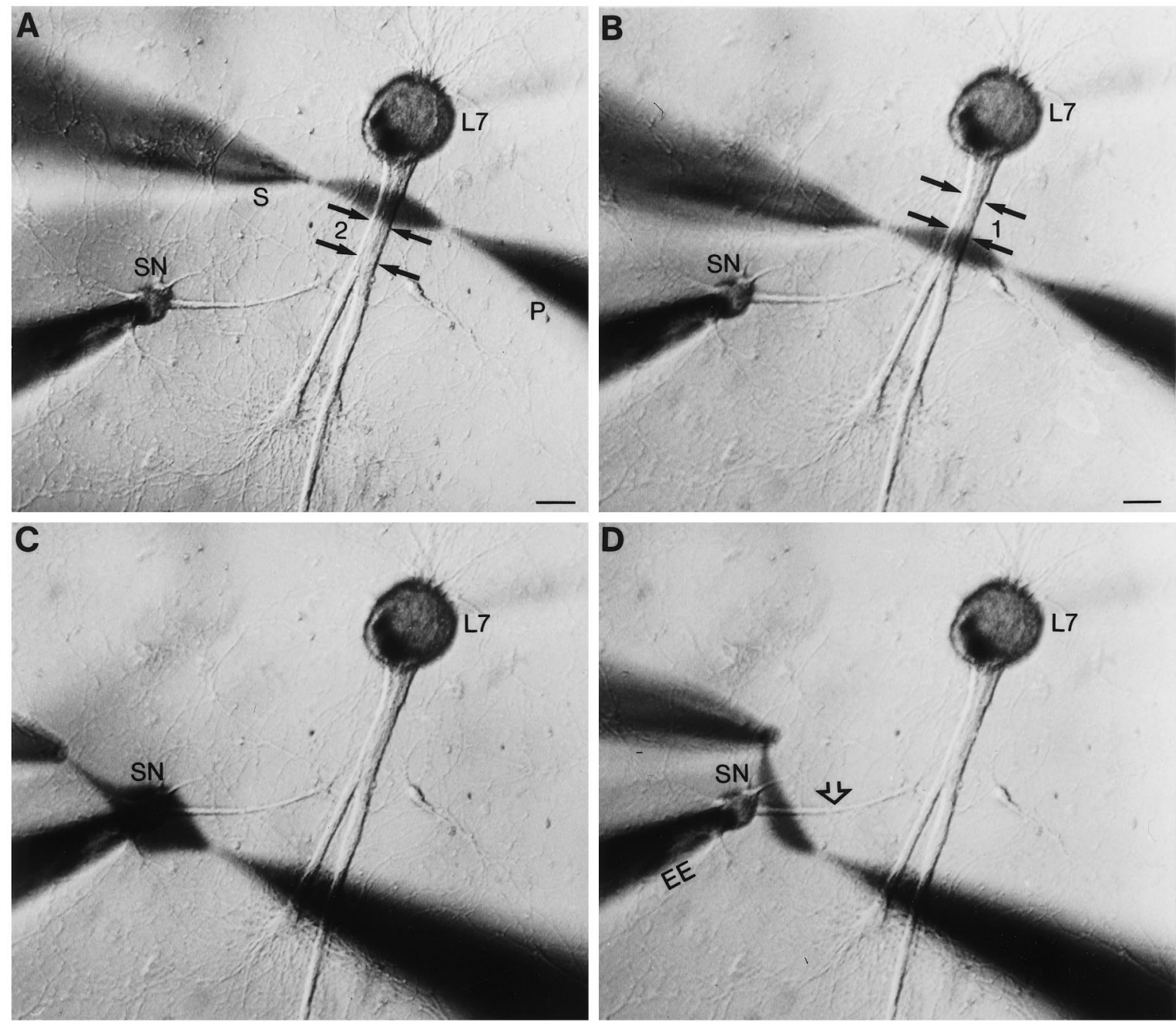

Figure 1. Focal application of neuromodulator to different portions of SN. $A-D$, Low-power phase-contrast micrographs of 4 d SN-L7 culture. Micropipettes for pressure injection $(P)$ and rapid suction $(S)$ of injected solutions are placed opposite a given region. The pressure and vacuum strengths needed to produce a stream of a given width are determined for each pair of pipettes before placement by the cells. The major axons of $L 7$ emerge from the L7 cell body and extend toward the bottom of the micrographs (double black arrows in $A$ and $B$ ). The axon of the $S N$ (open arrow in $D$ ) emerges from the SN cell body and extends toward the motor axons. The location of regenerated SN neurites and varicosities in contact with the motor axons is determined with epifluorescent microscopy after dye injections (see Figs. 2, 3). The extracellular electrode near the SN cell body is used to depolarize the cell to evoke an action potential. Intracellular electrode in L7 cell body (out-of-focus shadow extending in the top right of micrographs) is used to record EPSPs. $A, B$, Examples of focal streams of $\sim 50 \mu \mathrm{m}$ across two nonoverlapping regions of the motor axon. Zone 1 contained a high density of SN varicosities, whereas zone 2 contained proximal SN neurites with few varicosities. Scale bars, $50 \mu \mathrm{m}$. $C, D$, Examples of focal streams across the SN cell body $(C)$ and adjacent region of $\mathrm{SN}$ axon $(D)$.

and stabilized during the first $4 \mathrm{~d}$ in culture (Glanzman et al., 1989a, 1990; Schacher and Montarolo, 1991; Bank and Schacher, 1992; Sun and Schacher, 1996). Stable SN synapses show multiple forms of short-term heterosynaptic plasticity-presynaptic facilitation with bath applications of 5-HT (Rayport and Schacher, 1986; Dale and Kandel, 1990; Schacher et al., 1990; Sun and Schacher, 1996) and presynaptic depression with bath applications of FMRFamide (Belardetti et al., 1987; Montarolo et al., 1988; Dale and Kandel, 1990) - and will undergo a long-term change $(>24 \mathrm{hr})$ when the cultures are treated with repeated bath applications of 5-HT or FMRFamide (Montarolo et al., 1986, 1988; Schacher et al., 1990). The long-term changes in synapse efficacy evoked by 5-HT or FMRFamide are accompanied by changes in the number of $\mathrm{SN}$ varicosities contacting the motor axon (Glanzman et al., 1990; Schacher and Montarolo, 1991). SN varicosities in contact with the major axon of L7 either that form by day 4 in culture or that form after treatments with 5 -HT evoking long-term facilitation contain transmitter release sites (Glanzman et al., 1989a; Schacher et al., 1991). We therefore examined whether changes in synaptic efficacy after brief focal applications of 5-HT or FMRFamide are evoked when neuromodulators are applied to specific sites of SN-L7 interaction (see Fig. 1), including sites along the L7 axon that have a high or a low density of SN varicosities. Intracellular injection of dye into each $\mathrm{SN}$ was used to map the location of $\mathrm{SN}$ varicosities along the motor axon (Glanzman et al., 1989a, 1990; Bank and Schacher, 1992).

Brief application of 5-HT or FMRFamide to a region on the motor axon containing a high density of $\mathrm{SN}$ varicosities (6-12 varicosities in a $50 \mu \mathrm{m}$ zone along the motor axon) evoked facilitation or depression, respectively (Figs. 2, 3). After visualizing the location of the $\mathrm{SN}$ varicosities (Fig. $2 A, B$ ), 5-HT applied 


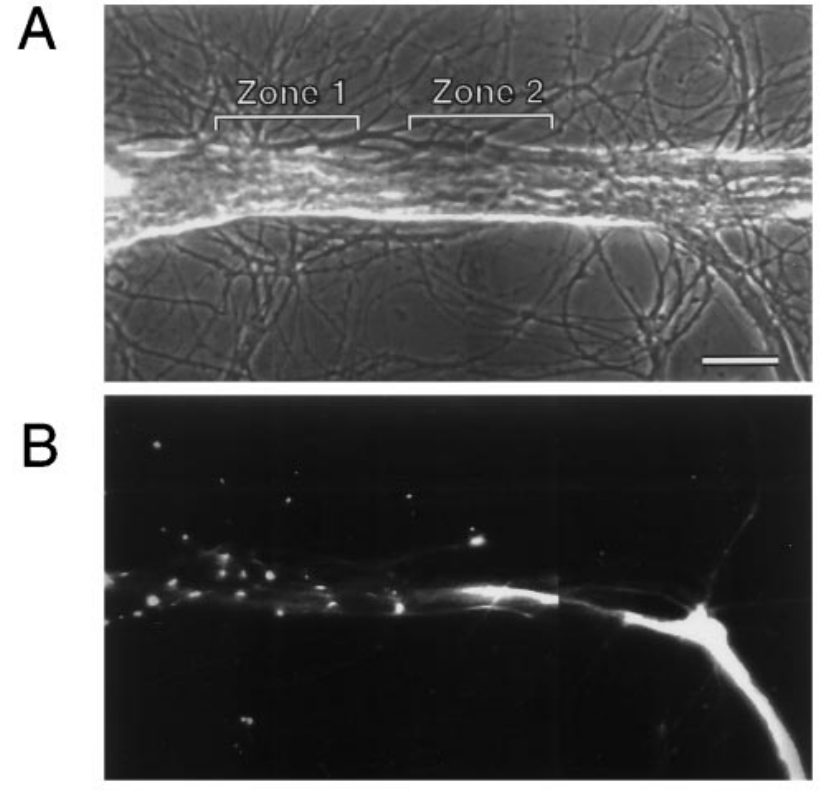

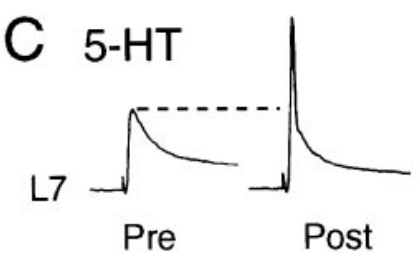

ZONE 1

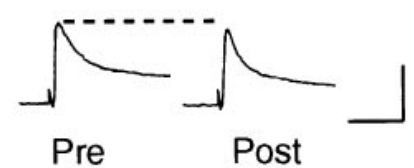

ZONE 2
Figure 2. Focal application of 5-HT to region with $\mathrm{SN}$ varicosities, but not SN neurites, evokes an increase in synaptic efficacy. $A$, Phase-contrast micrograph of a portion of motor axon. Zone 1 and Zone 2 indicate regions of focal applications of 5-HT. Scale bar, $25 \mu \mathrm{m}$. B, Epifluorescent micrograph of $\mathrm{SN}$ neurites and varicosities in the same region as $A$. Images from two focal planes were superimposed to identify all $\mathrm{SN}$ varicosities. Zone 1 contained nine varicosities, whereas zone 2 contained the contiguous SN neurites with two varicosities. The stump and distal portion of the $\mathrm{SN}$ axon are located in the bottom right of the micrograph. The SN cell body is $200 \mu \mathrm{m}$ from the portion of the axon in the bottom right. $C$, EPSPs evoked before (Pre) and after (Post) $20 \mathrm{sec}$ application of 5-HT to Zone 1 and Zone 2. The initial EPSPs were evoked $10 \mathrm{~min}$ before focal application, and test EPSPs were evoked $15 \mathrm{sec}$ after application. The initial EPSP for testing the effect of 5-HT on zone 2 was evoked 20 min after test EPSP for zone 1 . In half of the preparations, application to the zone with $\mathrm{SN}$ neurites preceded application to the zone with SN varicosities. Note that the EPSP triggered an action potential in L7 after 5-HT application to zone 1 . Vertical bar, $20 \mathrm{mV}$; horizontal bar, $50 \mathrm{msec}$.

to regions with $\mathrm{SN}$ varicosities evoked a significant increase in EPSP amplitude $(t=7.04 ; p<0.006)$ of $45.5 \pm 9.7 \%$ (Zone 1 in Fig. $2 ; n=4$ cultures). No significant change was evoked with application of 5-HT for up to $60 \mathrm{sec}$ to nearby regions of L7 axon that contained the proximal and contiguous SN neurites with few if any $\mathrm{SN}$ varicosities $(0-3)(-5.4 \pm 3.1 \%$; Zone 2 in Fig. 2). A parallel result was obtained with applications of FMRFamide. Brief applications to a region with a high density of $\mathrm{SN}$ varicosities (Zone 1 in Fig. 3; $n=4$ cultures) evoked a significant depression $(t=12.411 ; p<0.002)$ of $-53.9 \pm 3.3 \%$ in the amplitude of the EPSP compared to a change of $-15.7 \pm 5.6 \%$ when applied for up to $60 \mathrm{sec}$ to an adjacent region with SN neurites but few varicosities (Zone 2 in Fig. 3). These focal applications of neuromodulators ( $n=4$ for each neuromodulator) failed to evoke any significant change (from 0 to $\pm 10 \%$ ) in the membrane conduc-
A

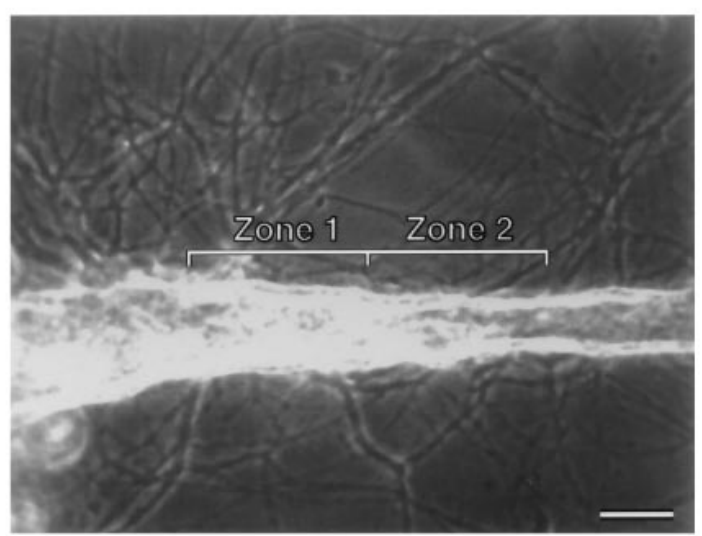

B

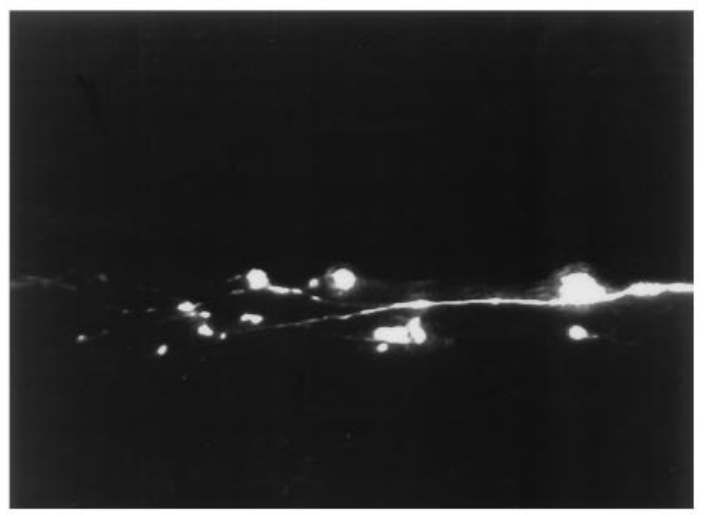

\section{FMRF}

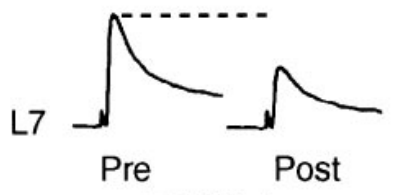

ZONE 1

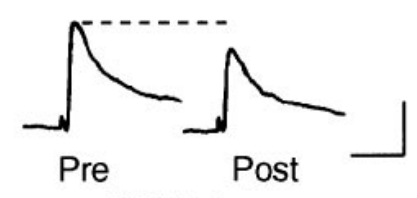

ZONE 2
Figure 3. Focal application of FMRFamide to region with $\mathrm{SN}$ varicosities, but not $\mathrm{SN}$ neurites, evokes a decline in synaptic efficacy. $A$, Phasecontrast micrograph of a portion of the motor axon. Zone 1 and Zone 2 indicate regions of focal applications of FMRFamide. Scale bar, $25 \mu \mathrm{m}$. $B$, Epifluorescent micrograph of SN neurites and varicosities in the same region as $A$. Images from two focal planes were superimposed to identify all SN varicosities. Zone 1 contained 11 varicosities, whereas zone 2 contained the contiguous SN neurites with three varicosities. The SN cell body is $\sim 400 \mu \mathrm{m}$ away from area in bottom right. $C$, EPSPs evoked before (Pre) and after (Post) $20 \mathrm{sec}$ application of FMRFamide to zone 1 and zone 2. The initial EPSPs were evoked $10 \mathrm{~min}$ before focal application, and test EPSPs were evoked $15 \mathrm{sec}$ after application. The initial EPSP for testing the effect of FMRFamide on zone 2 was evoked $20 \mathrm{~min}$ after the test EPSP for zone 1. In half of the preparations, the order of application to respective zones was reversed. Vertical bar, $10 \mathrm{mV}$; horizontal bar, $50 \mathrm{msec}$.

tance of L7. This is consistent with previous studies (Klein et al., 1980; Dale and Kandel, 1990) indicating that both neuromodulators evoke changes in synaptic efficacy primarily via actions that alter transmitter release from SN terminals.

Applications of the neuromodulators to the $\mathrm{SN}$ cell bodies failed to evoke a change in synaptic efficacy of nondepressed SN connections (Fig. 4). The EPSP amplitudes showed slight declines after brief applications of control solution (perfusion medium plus $0.02 \%$ Fast Green; $n=5$ ) to the region with SN varicosities and the $\mathrm{SN}$ cell body $(-17.8 \pm 3.1 \%$ and $-18.6 \pm 3.6 \%$, respectively). 
Figure 4. Focal applications of neuromodulators on $\mathrm{SN}$ varicosities, but not SN cell body, evoke change in the efficacy of nondepressed SN-L7 connections. $A 1$, Examples of EPSPs evoked before (Pre) and after (Post) focal applications of $0.02 \%$ Fast Green (Cont), 5-HT, or FMRFamide (FMRF) on the $\mathrm{SN}$ varicosities (Terminal) and SN cell body (Cell Body). Each row of EPSPs is generated from the same culture. The order of treatment was reversed in half of the cultures given applications of neuromodulators. Vertical bar, $10 \mathrm{mV}$; horizontal bar, $50 \mathrm{msec}$. $A 2$, Summary of the changes evoked with treatment. A twofactor ANOVA indicated an overall significant effect of treatment and location $\left(F_{(218)}=47.155 ; p<0.001\right)$. One-factor ANOVAs indicated that there was a significant effect of treatment with applications to SN terminals $(F=42.945 ; p<$ 0.001 ), but no significant effect of treatment with applications to SN cell bodies $(F=1.217 ; p>0.3)$.
A1
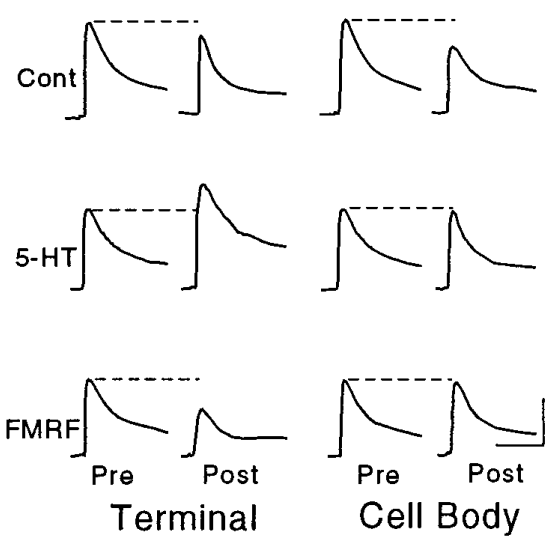

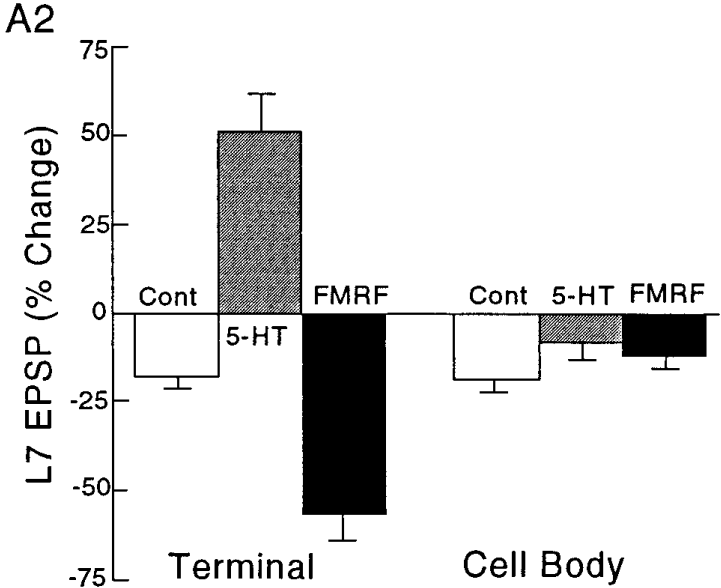

Application of 5-HT to the regions with $\mathrm{SN}$ varicosities $(n=8$ cultures) resulted in a significant increase in the amplitude of the EPSP of $51.0 \pm 10.8 \%$ (Dunnett's $t=5.143 ; p<0.01$ ), whereas application of 5-HT for up to $60 \mathrm{sec}$ to the cell bodies of the same SNs failed to evoke a significant change (Dunnett's $t=1.556 ; p>$ 0.2 ). The change evoked by 5-HT applied to regions along the L7 axon containing $\mathrm{SN}$ varicosities was significantly greater than the change evoked by 5-HT applied to the cell body (Scheffe's $F=$ 8.254; $p<0.01$ ). Similarly, application of FMRFamide to regions with SN varicosities ( $n=8$ cultures) depressed the EPSP amplitude by $-56.8 \pm 7.5 \%$ (Dunnett's $t=2.912 ; p<0.05$ ) compared to $-11.8 \pm 3.9 \%$ when applied for up to $60 \mathrm{sec}$ to the cell body (Dunnett's $t=1.043 ; p>0.3$ ). The decline with FMRFamide applied to SN varicosities along the axons of L7 was greater than the change evoked with applications to the SN cell body (Scheffe's $F=4.491 ; p<0.01)$.

Applications of the neuromodulators to regions along L7 axons with $\mathrm{SN}$ varicosities, but not to $\mathrm{SN}$ cell bodies, also modulated synaptic efficacy when connections were first depressed by lowfrequency stimulation of the SN (Fig. 5). Low-frequency stimulation (10-12 stimuli at $30 \mathrm{sec}$ intervals) evoked homosynaptic depression and reduced the efficacy of the synapses to $\sim 30 \%$ of the initial level. When the amplitude of the depressed EPSP just before neuromodulator application was normalized to $100 \%$, 5-HT applied to regions with $\mathrm{SN}$ varicosities increased significantly $(F=14.65 ; p<0.001)$ EPSP amplitude by about twofold to $204.1 \pm 19.3$ and $173.1 \pm 23.5 \%$, respectively, for the two EPSPs evoked after application ( $n=8$ cultures; Fig. $5 A)$. By contrast, application of the 5-HT to the cell bodies of the same SNs failed to evoke a significant change in the amplitudes of the two EPSPs evoked after application $(95.0 \pm 3.8$ and $93.0 \pm 8.5 \%$, respectively) of the EPSP amplitude recorded just before the application. FMRFamide evoked parallel changes (Fig. $5 B ; n=8$ cultures). When applied to regions with $\mathrm{SN}$ varicosities, FMRFamide depressed significantly $(F=13.855 ; p<0.001)$ the amplitude of the next two EPSPs to $40.0 \pm 4.5$ and $60.0 \pm 11.4 \%$, respectively, of the EPSP evoked before transmitter application. As was the case with 5-HT, applications to the cell bodies of the same SNs failed to evoke a significant change in the amplitude of the next two EPSPs (96.8 \pm 2.9 and $92.7 \pm 2.3 \%$, respectively; Fig. $5 B$ ).
Thus, short-term changes in synaptic efficacy with brief applications of 5-HT and FMRFamide are evoked only when the neuromodulators bind receptors at or close to $\mathrm{SN}$ varicosities.

\section{Distribution of receptors for evoking excitability changes in SN differ for 5-HT and FMRFamide and are regulated by interaction with the target}

In addition to evoking changes in synaptic efficacy, the neuromodulators evoke changes in SN excitability (Klein et al., 1986; Critz et al., 1991). We therefore assayed for changes in SN excitability with focal applications of the neuromodulators to determine whether binding to receptors at specific sites along the surface of SNs is required for evoking changes in excitability.

An excitability increase in SNs with focal application of 5-HT was evoked only when the neuromodulator was applied on the SN cell body, whereas an excitability decrease in SNs was evoked only when FMRFamide was applied focally to regions along the L7 axon with $\mathrm{SN}$ varicosities (Fig. 6).

Focal application of control solutions to any of the four regions depicted in Figure 1 evoked no change in SN excitability $(n=6$ cultures). Application of 5-HT to regions with $\mathrm{SN}$ varicosities (a site where 5-HT evoked a change in synapse efficacy; see Figs. 4, $5)$ failed to evoke any change in excitability, whereas application to the cell bodies of the same SNs ( $n=7$ cultures; see Fig. $1 C$ ) evoked a significant (Dunnett's $t=5.386 ; p<0.01$ ) increase of $2.4 \pm 0.3$ action potentials above the threshold response (Fig. 6). Applications of 5-HT to the cell body evoked a membrane depolarization of $4-10 \mathrm{mV}$ that fully reversed within $10 \mathrm{sec}$ when excitability was monitored with the next current injection. Applications to all other regions, including applications up to $60 \mathrm{sec}$ to the region of the SN axon nearest the cell body (see Fig. $1 D$ ), failed to evoke any significant membrane depolarizations (0-2 $\mathrm{mV}$ ) or excitability changes that could be detected by the intracellular electrode in the SN cell body.

Focal applications of FMRFamide evoked a change in $\mathrm{SN}$ excitability only when applied to a region along the L7 axon with $\mathrm{SN}$ varicosities (Fig. 6). Applications to regions with $\mathrm{SN}$ varicosities $(n=5$ cultures) evoked a significant (Dunnett's $t=12.095$; $p<0.01)$ decline of $-3.2 \pm 0.4$ action potentials, whereas applications to the cell bodies of the same SNs evoked a change of 

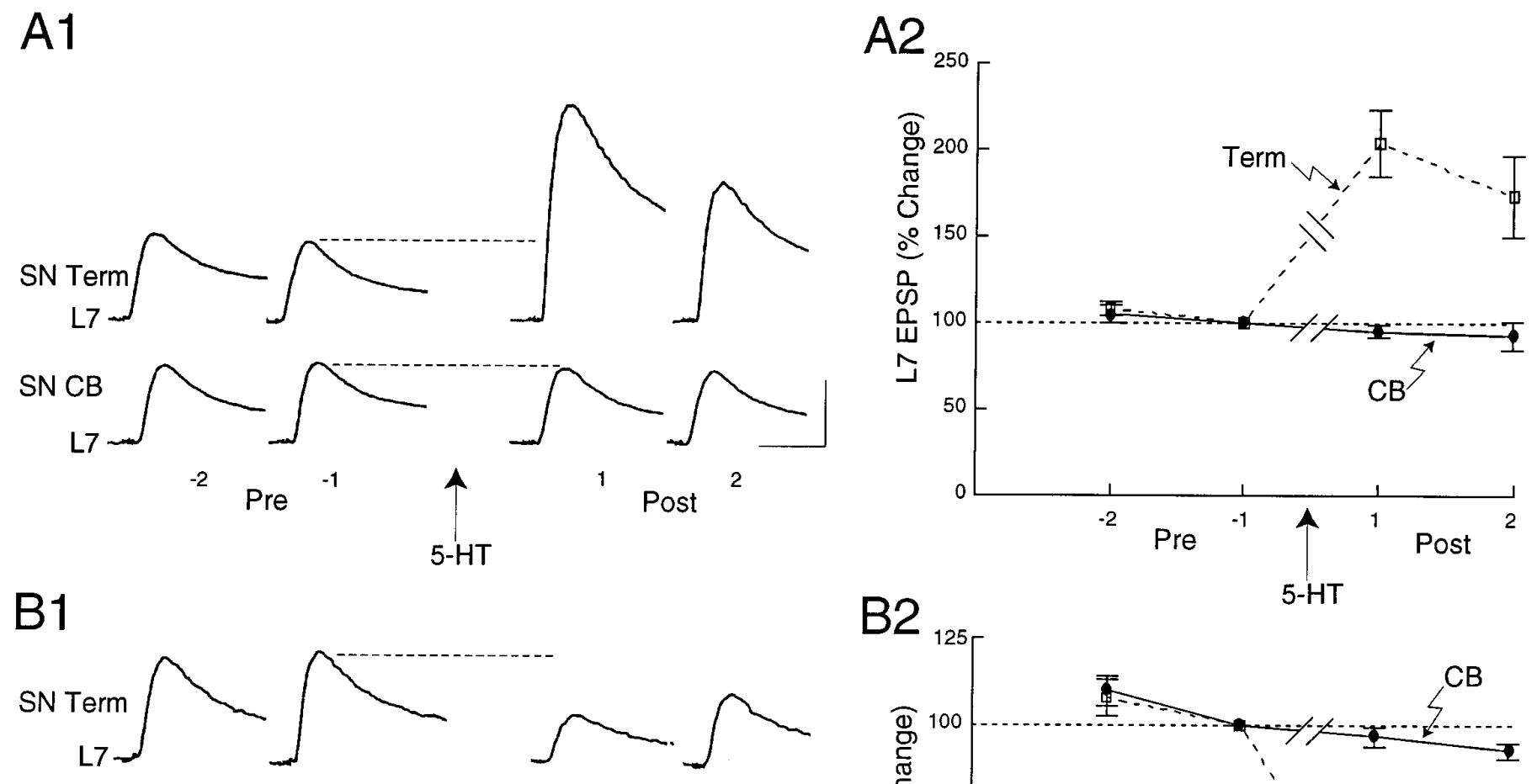

B2

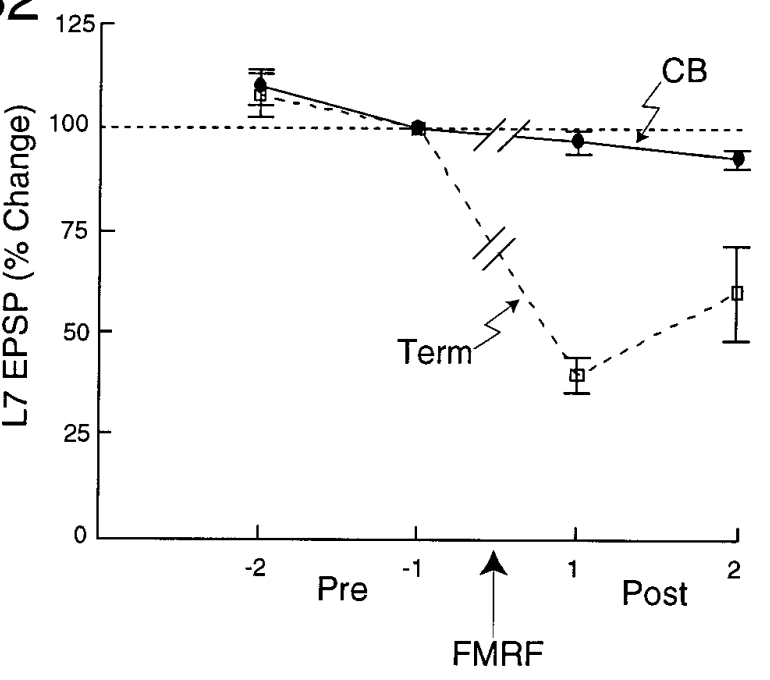

Figure 5. Focal applications of neuromodulators on SN varicosities, but not SN cell body, evoke change in the efficacy of SN-L7 connections first depressed by homosynaptic stimulation. A1, B1, Examples of two EPSPs evoked before (Pre; stimuli -2 and -1$)$ and after (Post; stimuli 1 and 2$)$ focal application of 5-HT $(A 1)$ or FMRFamide $(B 1)$ on the SN varicosities $(S N$ Term) and cell body $(S N C B)$. All EPSPs in $A 1$ and $B 1$ were evoked in the same culture. The order of application to each region was reversed for half of the cultures. A 20 min interval separated tests for change in synapse efficacy evoked by neuromodulator at different sites in each culture. Vertical bars, $10 \mathrm{mV}$; horizontal bars, $25 \mathrm{msec}$. $A 2, B 2$, Summary of the changes evoked by applications of 5-HT $(A 2)$ or FMRFamide $(B 2)$ on SN varicosities (Term) and SN cell body $(C B)$. Each point is the mean \pm SEM change in the EPSP normalized for each culture to the EPSP amplitude evoked just before application of neuromodulator (stimulus -1 ). One-factor ANOVAs indicated that both 5-HT and FMRFamide evoked significant changes in EPSP amplitude when applied to the varicosities but not to the cell bodies. Each EPSP evoked after applications of the neuromodulator to the varicosities was significantly different (Scheffe's $F$ tests) than the corresponding EPSP evoked after applications of the neuromodulator to the cell body.

$-0.4 \pm 0.5$ action potentials that was not significantly different (Dunnett's $t=0.855$ ) than the change evoked with control solution (Fig. 6). As was the case with 5-HT, there was a correspondence between evoking excitability change and membrane polarization. When applied to regions with $\mathrm{SN}$ varicosities, FMRFamide evoked transient hyperpolarizations of -5 to -13 $\mathrm{mV}$. The membrane began to repolarize during the application and typically recovered to baseline when excitability was tested. Applications to other regions, including regions with SN neurites without varicosities, evoked transient changes in membrane potential from -2 to $+1 \mathrm{mV}$. Applications of FMRFamide for up to $60 \mathrm{sec}$ to regions with $\mathrm{SN}$ neurites and few varicosities $(n=4$ cultures) failed to evoke a significant change in excitability (a decline of one action potential in one of the four cultures examined; data not shown).
We recently found (Sun and Schacher, 1996) that the presence of the target motor cell regulates the relative distribution of different functional 5-HT receptors. We therefore examined the ability to modulate excitability with applications of neuromodulators on the cell bodies of SNs maintained in culture alone without a motor cell. Under these conditions (Fig. 7), application of either 5 -HT ( $n=5$ cultures) or FMRFamide ( $n=5$ cultures) evoked significant changes in excitability compared to controls $(n=5$ cultures). Application of 5-HT resulted in a significant increase of $4.2 \pm 0.7$ action potentials (Dunnett's $t=5.612 ; p<0.01$ ), an increase that is larger than the one evoked when 5-HT is focally applied to the SN cell body in the presence of L7 (see Fig. 6B; Scheffe's $F=2.755 ; p<0.04$ ). In the absence of $\mathrm{L} 7$, focal application of FMRFamide on the SN cell body now evoked a significant decrease (Dunnett's $t=4.009 ; p<0.01$ ) in excitability 
Figure 6. Focal applications of 5-HT to SN cell body and focal application of FMRFamide to $\mathrm{SN}$ varicosities evoke changes in SN excitability in SN-L7 cocultures. $A$, Examples of responses to depolarizing current pulses before (Pre) and after (Post) focal applications of Fast Green (Cont), 5-HT, or FMRFamide $(F M R F)$ to $\mathrm{SN}$ varicosities (Terminal) and SN cell body (Cell Body). Note that a change in the number of action potentials was evoked only when FMRFamide was applied to $\mathrm{SN}$ varicosities or 5-HT to SN cell body. B, Summary of the changes in excitability evoked with treatment. A two-factor ANOVA indicated an overall effect of treatment $\left(F_{(2,15)}=17.616 ; p<0.001\right)$. One-factor ANOVAs indicated that there was a significant effect of treatment for 5-HT (cell body: $F=25.759$; $p<0.001$ ) and FMRFamide (terminal: $F=87.789 ; p<0.001)$. Vertical bar, 25 $\mathrm{mV}$; horizontal bar, $400 \mathrm{msec}$.

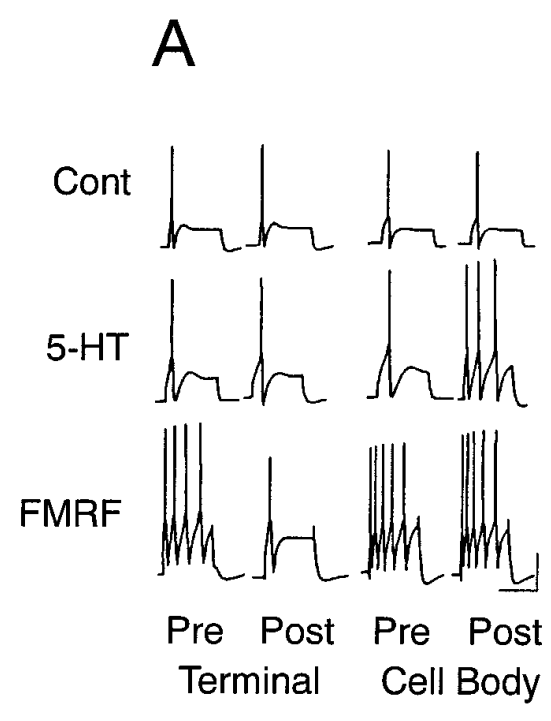

B

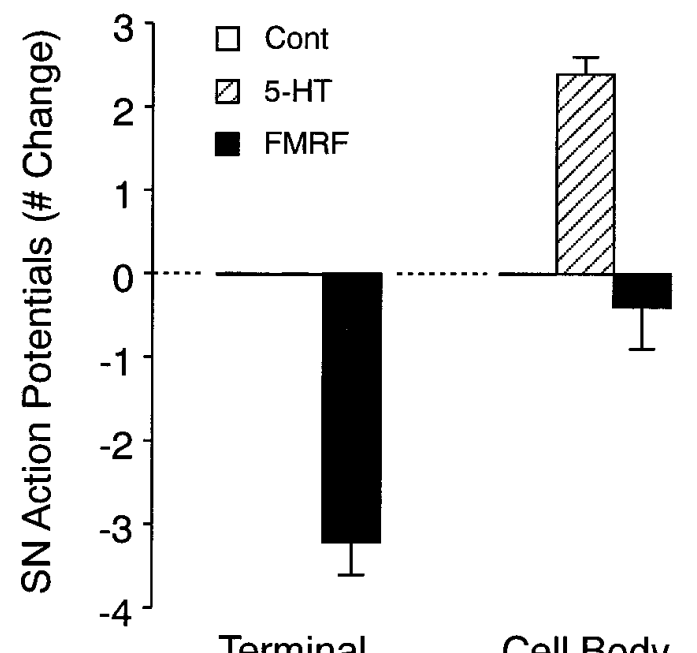

of $-3.0 \pm 0.6$ action potentials (Fig. 7). This change was significantly different than the change evoked by FMRFamide applied to the cell bodies of SNs that interact with L7 (see Fig. 6B; Scheffe's $F=3.703 ; p<0.02$ ). Thus, interaction with L7 appears to lead to an alteration in the local distribution of functional receptors for neuromodulators on the surface of the SN.

\section{DISCUSSION}

The results reported here extend earlier studies on the sitespecific actions of neuromodulators (Clark and Kandel, 1984; Hammer et al., 1989; Clark and Cooper, 1993; Emptage and Carew, 1993) and suggest that functional receptors for 5-HT and FMRFamide on SNs that have established stable, fast excitatory contacts with a target neuron are not distributed uniformly. Functional receptors for 5-HT are enriched at or near SN varicosities to mediate short-term changes in synaptic efficacy, and at the cell body to mediate short-term changes in excitability. FMRFamide receptors are enriched at or near $\mathrm{SN}$ varicosities where they mediate changes in both synaptic efficacy and excitability. The differential distribution of receptors on the surface of SNs that interact with a single target cell in vitro parallels the distribution for these receptors that is predicted by the pattern of immunostaining for varicosities that contain the neuromodulators in the intact nervous system of Aplysia. Detectable immunoreactive staining for 5-HT is found both in varicosities directly apposed to the surface of $\mathrm{SN}$ cell bodies and other cells in the central ganglia and in processes and varicosities in the neuropil of the ganglia (Kistler et al., 1985; Zhang et al., 1991). By contrast, strong immunoreactive staining for FMRFamide is primarily concentrated in processes and varicosities in the neuropil and within the cell bodies of neurons that synthesize the neuropeptide, but is
Figure 7. Focal applications of 5-HT or FMRFamide on SN cell body evoke changes in excitability in SNs plated alone. $A$, Examples of responses to depolarizing current pulses before (Pre) and after (Post) focal applications of Fast Green (Cont), 5-HT, or FMRFamide (FMRF) to cell bodies of SNs plated alone. Vertical bar, $20 \mathrm{mV}$; horizontal bar, $300 \mathrm{msec}$. $B$, Summary of the changes in excitability. A one-factor ANOVA indicated a significant effect of treatment $\left(F_{(2,12)}=46.714 ; p<0.001\right)$.

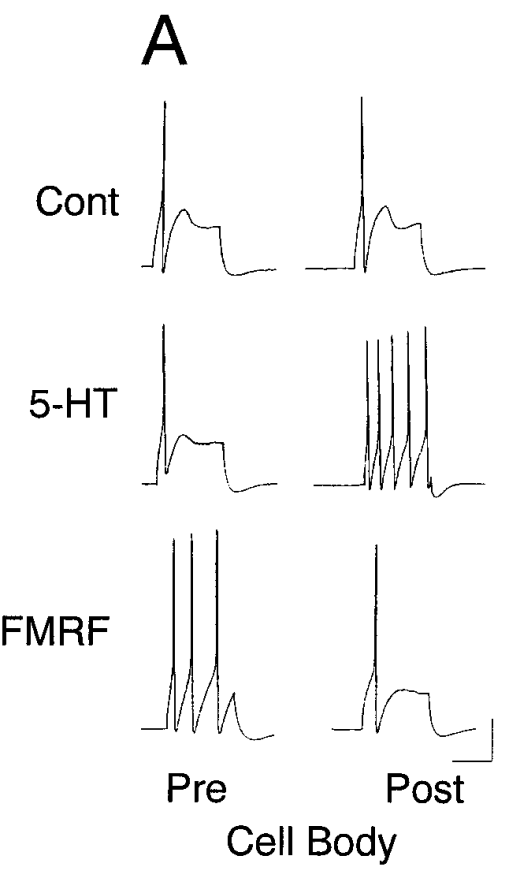

B

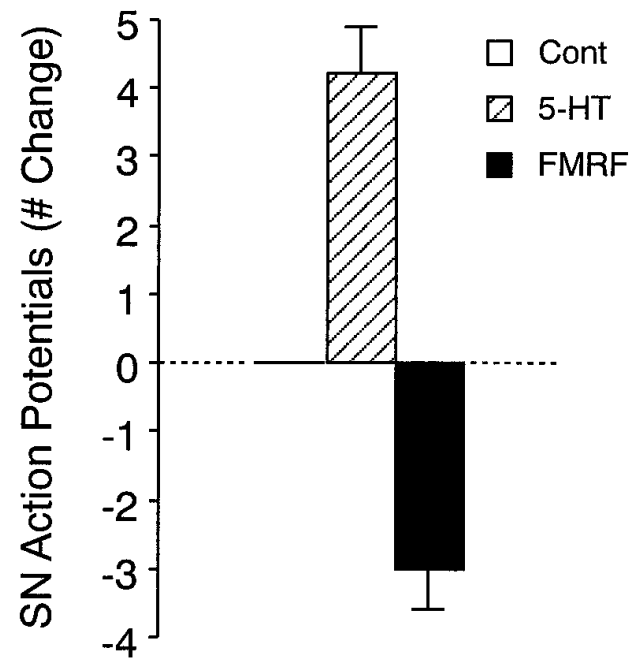

Cell Body 
rarely observed in varicosities directly apposed to neuronal cell bodies (Brown et al., 1985; Schaefer et al., 1985; Lloyd et al., 1987). Furthermore, our results in culture suggest that the differential distribution of G-protein-coupled receptors for neuromodulators on a presynaptic neuron can be regulated by interactions between the presynaptic neuron and its own targets, and does not require direct interactions with interneurons that synthesize and release the neuromodulators.

The site-specific actions of the neuromodulators on changes in synaptic efficacy or excitability most likely are attributable to uneven distribution of functional receptors along the surface of the SNs and not to a restriction in the diffusion of locally generated second messengers to the critical areas (terminals or cell body) where changes in function are expressed. Functional receptors for FMRFamide appear to be highly enriched at regions with $\mathrm{SN}$ varicosities. FMRFamide evoked a transient but large hyperpolarization in the SN cell body with applications to distal varicosities, but little or no hyperpolarization when neuromodulator was applied to neurites in more proximal regions or to the $\mathrm{SN}$ cell body itself. Receptors for 5-HT appear to be enriched in regions at or near $\mathrm{SN}$ varicosities and on the $\mathrm{SN}$ cell body. Local applications of neuromodulators to SN neurites adjacent (within 50 $\mu \mathrm{m}$ ) to regions with $\mathrm{SN}$ varicosities or to $\mathrm{SN}$ axon adjacent to the cell body failed to evoke significant changes in the properties of SNs. This distance is small enough to allow the diffusion of cAMP the levels in varicosities and processes of which are increased significantly with bath applications of 5-HT (Backsai et al., 1993). In addition, cAMP injected directly into the $\mathrm{SN}$ cell body can diffuse rapidly in some instances and for considerable distances $(250-500 \mu \mathrm{m})$ to $\mathrm{SN}$ terminals to evoke increases in synapse efficacy (Schacher et al., 1993).

Our results suggest that interaction with a postsynaptic target influences the distribution of functional presynaptic receptors for neuromodulators. There appears to be a net decrease in density of functional receptors for the neuromodulators on the $\mathrm{SN}$ cell bodies when SNs interact and form connections with L7. The same local applications of FMRFamide that failed to evoke a change in excitability when SNs are in contact with L7 evoked significant changes in excitability when SNs were plated alone. The apparent density of functional receptors for 5-HT on SN cell bodies is also reduced when SNs are in contact with L7. We recently reported (Sun and Schacher, 1996) that interaction with L7 also affected the distribution of different functional receptors for 5-HT (Mercer et al., 1991; Emptage and Carew, 1993). In the absence of the target, excitability changes evoked by 5-HT are mediated primarily by cyproheptidine/methiothepin-sensitive receptors. In the presence of a target neuron and synaptic connections, excitability changes are mediated primarily by other receptors insensitive to the 5-HT antagonists. In addition, there was a time-dependent increase in the contribution of antagonistsensitive receptors toward enhancement of synaptic efficacy with 5-HT. These results (Sun and Schacher, 1996) plus results reported here suggest that interaction with the target cell L7 leads to changes in the distribution of functional receptors for FMRFamide on the cell body, for cyproheptidine/methiothepin-sensitive 5-HT receptors at or near the $\mathrm{SN}$ varicosities, and for these same functional receptors on the SN cell body.

The distribution of functional receptors for 5-HT and FMRFamide on the surface of SN cell bodies and the regenerated SN neurites and varicosities in culture occurs in the absence of neurons that synthesize or release 5-HT or FMRFamide. This distribution parallels the distribution that might be expected in the intact nervous system (see above). Our results raise the possibility that enrichment of G-protein-coupled receptors to 5-HT and FMRFamide at or near SN terminals in vitro may be an intrinsic property of the presynaptic structures that develop and mature as transmitter release sites with specific plastic capabilities. These receptors for neuromodulators may be utilized first by developing presynaptic growth cones to respond to environmental cues as they extend and form stable connections (Haydon et al., 1984; Goldberg et al., 1989). The growth cones of regenerating SNs (Belardetti et al., 1986) as well as growth cones of neurons in other invertebrate and vertebrate systems have receptors and appropriate signal transduction machinery for responding to neuromodulators (Lohof et al., 1992; Davenport et al., 1993; Zheng et al., 1994; Kater and Rehder, 1995). With maturation, other cellcell interactions between the postsynaptic target and presynaptic terminals may refine the overall density of a specific receptor or relative contribution of different receptor subtypes expressed by the presynaptic neuron (Sun and Schacher, 1996). Future studies will be directed at determining the identity of the extracellular signals and intracellular pathways by which cell-cell interactions influence the expression and distribution of receptors and their signal transduction machinery mediating different forms of synaptic plasticity.

\section{REFERENCES}

Anderson MJ, Cohen MW (1977) Nerve-induced and spontaneous redistribution of acetylcholine receptors on cultured muscle cells. J Physiol (Lond) 268:757-773.

Backsai BJ, Hochner B, Mahaut-Smith M, Adams SR, Kaang B, Kandel ER, Tsien RY (1993) Spatially resolved dynamics of cAMP and protein kinase A subunits in Aplysia sensory neurons. Science 260:222-226.

Bank M, Schacher S (1992) Segregation of presynaptic inputs on an identified target neuron in vitro: structural remodeling visualized over time. J Neurosci 12:2960-2972.

Baxter DA, Byrne JH (1990) Differential effects of cAMP and serotonin on membrane current, action potential duration, and excitability in somata of pleural sensory neurons of Aplysia. J Neurophysiol 64:978-990.

Belardetti F, Schacher S, Kandel ER, Siegelbaum SA (1986) The growth cones of Aplysia sensory neurons: modulation by serotonin of action potential duration and single potassium channel currents. Proc Natl Acad Sci USA 83:7094-7098.

Belardetti F, Kandel ER, Siegelbaum SA (1987) Neuronal inhibition by the peptide FMRFamide involves opening of S-potassium channels. Nature 325:153-156.

Bernier L, Castellucci VF, Kandel ER, Schwartz JH (1982) Facilitatory transmitter causes a selective and prolonged increase in cyclic AMP in sensory neurons mediating the gill and siphon withdrawal reflex in Aplysia. J Neurosci 2:1682-1691.

Braha O, Dale N, Hochner B, Klein M, Abrams TW, Kandel ER (1990) Second messengers involved in the two processes of presynaptic facilitation that contribute to sensitization and dishabituation in Aplysia sensory neurons. Proc Natl Acad Sci USA 87:2040-2044.

Brunelli M, Castellucci VF, Kandel ER (1976) Synaptic facilitation and behavioral sensitization in Aplysia: possible role of serotonin and cyclic AMP. Science 194:1178-1181.

Brown RO, Gusman D, Basbaum AI, Mayeri E (1985) Identification of Aplysia neurons containing immunoreactive FMRFamide. Neuropeptides 6:517-526.

Byrne JH, Kandel ER (1996) Presynaptic facilitation revisited: state and time dependence. J Neurosci 16:425-435.

Buttner N, Siegelbaum SA, Volterra A (1989) Direct modulation of Aplysia S-potassium channels by a 12-lipoxygenase metabolite of arachidonic acid. Nature 342:553-555.

Castellucci VF, Kandel ER, Schwartz JH, Wilson AC, Nairn A, Greengard P (1980) Intracellular injection of the catalytic subunit of cyclic AMPdependent protein kinase stimulates facilitation of transmitter release underlying behavioral sensitization in Aplysia. Proc Natl Acad Sci USA 77:7492-7496. 
Clark GA, Cooper J (1993) Synapse-specific inhibition by FMRFamide at Aplysia sensorimotor connections. Soc Neurosci Abstr 19:18.

Clark GA, Kandel ER (1984) Branch-specific heterosynaptic facilitation in Aplysia siphon sensory cells. Proc Natl Acad Sci USA 81:2577-2581.

Critz SD, Baxter DA, Byrne JH (1991) Modulatory effects of serotonin, FMRFamide, and myomodulin on the duration of action potentials, excitability, and membrane currents in tail sensory neurons of Aplysia. J Neurophysiol 66:1912-1926.

Dale N, Kandel ER (1990) Facilitatory and inhibitory transmitters modulate spontaneous transmitter release at cultured Aplysia sensorimotor synapses. J Physiol (Lond) 421:203-222.

Dale N, Kandel ER (1993) L-Glutamate may be the fast excitatory transmitter of Aplysia sensory neurons. Proc Natl Acad Sci USA 90:7163-7167.

Dale N, Kandel ER, Schacher S (1987) Serotonin produces long-term changes in the excitability of Aplysia sensory neurons in culture that depend on new protein synthesis. J Neurosci 7:2232-2238.

Dale N, Schacher S, Kandel ER (1988) Long-term facilitation in Aplysia involves increase in transmitter release. Science 239:282-285.

Dan Y, Poo MM (1994) Retrograde interactions during formation and elimination of neuromuscular synapses. Curr Opin Neurobiol 4:95-100.

Davenport RW, Dou P, Rehder V, Kater SB (1993) A sensory role for neuronal growth cone filopodia. Nature 361:721-724.

Drapeau P, Catarsi S, Merz DC (1995) Signaling synapse formation between identified neurons. J Physiol (Paris) 89:115-123.

Emptage NJ, Carew TJ (1993) Long-term synaptic facilitation in the absence of short-term facilitation in Aplysia neurons. Science 262:253-256.

Falls DL, Harris DA, Johnson FA, Morgan MM, Corfas G, Fischbach GD (1990) ARIA: a protein that may regulate the accumulation of acetylcholine receptors at developing chick neuromuscular junction. Cold Spring Harb Symp Quant Biol 50:397-406.

Frank E, Fischbach GD (1979) Early events in neuromuscular junction formation in vitro: induction of acetylcholine receptor clusters in the postsynaptic membrane and morphology of newly formed synapses. $\mathbf{J}$ Cell Biol 83:143-158.

Gapon S, Kupfermann I (1996) Evidence for transmitter similarity of two classes of mechanoreceptor neurons in the cerebral ganglion of Aplysia. Neurosci Lett 205:157-160.

Glanzman DL, Kandel ER, Schacher S (1989a) Identified target motor neuron regulates neurite outgrowth and synapse formation of Aplysia sensory neurons in vitro. Neuron 3:441-450.

Glanzman DL, Mackey SL, Hawkins RD, Dyke AM, Lloyd PE, Kandel ER (1989b) Depletion of serotonin in the nervous system of Aplysia reduces the behavioral enhancement of gill withdrawal as well as the heterosynaptic facilitation produced by tail shock. J Neurosci 9:4200-4213.

Glanzman DL, Kandel ER, Schacher S (1990) Target-dependent structural changes accompanying long-term synaptic facilitation in Aplysia neurons. Science 249:799-802.

Goldberg DJ, Schacher S (1996) Culturing the large identified neurons of Aplysia. In: Culturing nerve cells, 2nd Ed (Banker G, Goslin K, eds). Cambridge, MA: MIT, in press.

Goldberg JI, Mills LR, Kater SB (1991) Novel effects of serotonin on neurite outgrowth in neurons cultured from embryos of Helisoma trivolvis. J Neurobiol 22:182-194.

Hall ZW, Sanes JR (1993) Synaptic structure and development: the neuromuscular junction. Neuron 10:99-122.

Hammer M, Cleary LJ, Byrne JH (1989) Serotonin acts in the synaptic region of sensory neurons in Aplysia to enhance transmitter release. Neurosci Lett 104:235-240.

Haydon PG, McCobb DP, Kater SB (1984) Serotonin selectively inhibits growth cone motility and synaptogenesis of specific identified neurons. Science 226:561-564.

Hochner B, Klein M, Schacher S, Kandel ER (1986) Additional components in the cellular mechanism of presynaptic facilitation contributes to behavioral dishabituation in Aplysia. Proc Natl Acad Sci USA 83:8794-8798.

Kater SB, Rehder V (1995) The sensory-motor role of growth cone filopodia. Curr Opin Neurobiol 5:68-74.

Kistler HB, Hawkins RD, Koester J, Steinbusch HWM, Kandel ER, Schwartz JH (1985) Distribution of serotonin-immunoreactive cell bodies and processes in the abdominal ganglion of mature Aplysia. J Neurosci 5:72-80.
Klein M, Schapiro E, Kandel ER (1980) Synaptic plasticity and modulation of the calcium current. J Exp Biol 89:117-157.

Klein M, Hochner B, Kandel ER (1986) Facilitatory transmitters and cAMP can modulate accommodation as well as transmitter release in Aplysia sensory neurons: evidence for parallel processing in a single cell. Proc Natl Acad Sci USA 83:7994-7998.

Li XC, Giot JF, Kuhl D, Hen R, Kandel ER (1995) Cloning and characterization of two related serotonergic receptors from the brain and the reproductive system of Aplysia that activate phospholipase C. J Neurosci 15:7585-7591.

Lloyd PE, Frankfurt M, Stevens P, Kupfermann I, Weiss KR (1987) Biochemical and immunocytochemical localization of the neuropeptides FMRFamide, SCPA, SCPB, to neurons involved in the regulation of feeding in Aplysia. J Neurosci 7:1123-1132.

Lohof AM, Quillan M, Day Y, Poo MM (1992) Asymmetric modulation of cytosolic cAMP activity induces growth cone turning. J Neurosci 12:1253-1261.

Mackey SL, Kandel ER, Hawkins RD (1989) Identified serotonergic neurons LCB1 and RCB1 in the cerebral ganglion of Aplysia produce presynaptic facilitation of siphon sensory neurons. J Neurosci 9:4227-4235

McMahan UJ, Wallace BG (1989) Molecules in the basal lamina that direct the formation of synaptic specializations at neuromuscular junctions. Dev Neurosci 11:227-247.

Mercer AR, Emptage NJ, Carew TJ (1991) Pharmacological dissociation of modulatory effects of serotonin in Aplysia sensory neurons. Science 254:1811-1813.

Montarolo PG, Goelet P, Castellucci VF, Morgan J, Kandel ER, Schacher $S$ (1986) A critical time window for macromolecular synthesis in longterm heterosynaptic facilitation in Aplysia. Science 234:1249-1254.

Montarolo PG, Kandel ER, Schacher S (1988) Long-term heterosynaptic inhibition in Aplysia. Nature 333:171-174.

Occor KA, Byrne JH (1985) Membrane responses and changes in cyclic AMP levels in Aplysia neurons by serotonin, tryptamine, FMRFamide, and small cardioactive peptide (SCPb). Neurosci Lett 55:113-118.

Pieroni JP, Byrne JH (1992) Differential effects of serotonin, FMRFamide, and small cardioactive peptide on multiple, distributed processes modulating sensorimotor synaptic transmission in Aplysia. J Neurosci 12:2633-2647.

Piomelli D, Volterra A, Dale N, Siegelbaum SA, Kandel ER, Schwartz JH, Belardetti F (1987) Lipoxygenase metabolites of arachidonic acid as second messengers for presynaptic inhibition of Aplysia sensory cells. Nature 328:38-43.

Rayport SG, Schacher S (1986) Synaptic plasticity in vitro: cell culture of identified Aplysia neurons mediating short-term habituation and sensitization. J Neurosci 6:759-763.

Rosen SC, Susswein AJ, Cropper EC, Weiss KR, Kupfermann I (1989) Selective modulation of spike duration by serotonin and the neuropeptides, FMRFamide, $\mathrm{SCPb}$, buccalin and myomodulin in different classes of mechanoafferent neurons in the cerebral ganglion of Aplysia. J Neurosci 9:390-402.

Saktor TC, Schwartz JH (1990) Sensitizing stimuli cause translocation of protein kinase C in Aplysia sensory neurons. Proc Natl Acad Sci USA 87:2036-2039.

Schacher S (1985) Differential synapse formation and neuritic outgrowth at two branches of the metacerebral cell of Aplysia in dissociated cell culture. J Neurosci 5:2028-2034.

Schacher S, Montarolo PG (1991) Target-dependent structural changes in sensory neurons of Aplysia accompany long-term heterosynaptic inhibition. Neuron 6:679-690.

Schacher S, Proshansky E (1983) Neurite regeneration by Aplysia neurons in dissociated cell culture: modulation by Aplysia hemolymph and the presence of the initial axon segment. J Neurosci 3:2403-2413.

Schaefer M, Piccioto M, Kreiner T, Kaldany RR, Taussig R, Sheller RH (1985) Aplysia neurons express a gene encoding multiple FMRFamide neuropeptides. Cell 41:467-467.

Schacher S, Montarolo PG, Kandel ER (1990) Selective short- and longterm effects of serotonin, small cardioactive peptide, and tetanic stimulation on sensorimotor synapses of Aplysia in culture. J Neurosci 10:3286-3294.

Schacher S, Glanzman DL, Barzilai A, Dash P, Grant SGN, Keller F, Mayford M, Kandel ER (1991) Long-term facilitation in Aplysia: persistent phosphorylation and structural changes. Cold Spring Harb Symp Quant Biol 55:187-202. 
Schacher S, Kandel ER, Montarolo PG (1993) cAMP and arachidonic acid simulate long-term structural and functional changes produced by neurotransmitters in Aplysia sensory neurons. Neuron 10:1079-1088.

Siegelbaum SA, Camardo JS, Kandel ER (1982) Serotonin and cAMP close single $\mathrm{K}^{+}$channels in Aplysia sensory neurons. Nature 299:413-417.

Small SA, Cohen TE, Kandel ER, Hawkins RD (1992) Identified FMRFamide-immunoreactive neuron LPL16 in the left pleural ganglion of Aplysia produces presynaptic inhibition of siphon sensory neurons. J Neurosci 12:1616-1627.

Sossin WS, Schwartz JH (1992) Selective activation of calcium-activated PKCs in Aplysia neurons by 5-HT. J Neurosci 9:3218-3229.

Stoop R, Poo MM (1995) Potentiation of transmitter release by ciliary neurotrophic factor requires somatic signaling. Science 267:695-699.

Sugita S, Goldsmith JR, Baxter DA, Byrne JH (1992) Involvement of protein kinase $\mathrm{C}$ in serotonin-induced spike broadening and synaptic facilitation of sensorimotor connections in Aplysia. J Neurophysiol 68:643-651.

Sun ZY, Schacher S (1996) Development of short-term heterosynaptic facilitation at Aplysia sensorimotor synapses in vitro is accompanied by changes in the functional expression of presynaptic serotonin receptors. $\mathrm{J}$ Neurophysiol, in press.

Trudeau LE, Castellucci VF (1993) Excitatory amino acid neurotransmission at sensory-motor and interneuronal synapses of Aplysia californica. J Neurophysiol 70:1221-1230.

Xu Y, Cleary LJ, Byrne JH (1994) Identification and characterization of pleural neurons that inhibit tail sensory neurons and motor neurons in Aplysia: correlation with FMRFamide immunoreactivity. J Neurosci 14:3565-3577.

Zhang ZS, Fang B, Marshak DW, Byrne JH, Cleary LJ (1991) Serotonergic varicosities make synaptic contacts with pleural sensory neurons of Aplysia. J Comp Neurol 311:259-270.

Zheng JQ, Felder M Connor JA, Poo MM (1994) Turning of nerve growth cones induced by neurotransmitters. Nature 368:140-144.

Zhu H, Wu F, Schacher S (1994) Aplysia cell adhesion molecules and serotonin regulate sensory cell-motor cell interactions during early stages of synapse formation in vitro. J Neurosci 14:6886-6900.

Zoran MJ, Doyle RT, Haydon PG (1990) Target-dependent induction of secretory capabilities in an identified motoneuron during synaptogenesis. Dev Biol 138:202-13. 